\title{
$P L X N A 2$ identified as a candidate gene by genome-wide association analysis for mandibular prognathism in human chondrocytes
}

\author{
TAKASHI S. KAJII ${ }^{1}$, AKIRA OKA ${ }^{2}$, MITSUTOKI HATTA ${ }^{3}$, \\ JUN YAMAZAKI $^{3}$, JUNRO YAMASHITA ${ }^{4}$ and JUNICHIRO IIDA ${ }^{5}$
}

\author{
${ }^{1}$ Section of Orthodontics, Department of Oral Growth and Development, Fukuoka Dental College, Fukuoka 814-0913; \\ ${ }^{2}$ Institute of Medical Science, Tokai University, Kanagawa 259-1193; ${ }^{3}$ Section of Cellular and Molecular Regulation, \\ Department of Physiological Science and Molecular Biology and ${ }^{4}$ Section of Fixed Prosthodontics, \\ Department of Oral Rehabilitation, Fukuoka Dental College, Fukuoka 814-0913; \\ ${ }^{5}$ Department of Orthodontics, Division of Oral Functional Science, Graduate School \\ of Dental Medicine, Hokkaido University, Sapporo 060-8586, Japan
}

Received February 23, 2018; Accepted July 3, 2018

DOI: 10.3892/br.2018.1128

\begin{abstract}
In a previous genome-wide association study, plexin A2 (PLXNA2) was suggested as one of the candidate genes for mandibular prognathism. PLXNA2 encodes plexin A2, a member of the plexin-A family of semaphorin co-receptors. Semaphorin 3A (sema3A) exerts an osteoprotective effect. However, to the best of our knowledge, there have been no previous studies examining the role of sema3A or plexin A2 on human chondrocytes. The objectives of the present study were to examine the function of sema3A and its receptor, plexin $\mathrm{A} 2$, in human chondrocytes. Normal human chondrocytes were cultured in media with either a high $(100 \mathrm{ng} / \mathrm{ml})$ or a low $(1 \mathrm{ng} / \mathrm{ml})$ concentration of sema3A, or without sema3A as a control. Cells and extracellular matrices were assayed for concentrations of protein and parathyroid hormone-related peptide receptor 1 (PTH-R1) using a bicinchoninic acid assay and an enzyme immunoassay, respectively. At culture day 7, the high and low concentrations of exogenous sema3A significantly increased the protein content compared with the control ( $\mathrm{P}=0.0008$ and 0.00002 , respectively). At culture day 14 , a high concentration of exogenous sema $3 \mathrm{~A}$ significantly increased the protein content and decreased the concentration of PTH-R1 compared with the control $(\mathrm{P}=0.002)$. The present study revealed novel results that exogenous sema3A suppresses the expression of PTH-R1 in human
\end{abstract}

Correspondence to: Dr Takashi S. Kajii, Section of Orthodontics, Department of Oral Growth and Development, Fukuoka Dental College, 2-15-1 Tamura, Sawara-ku, Fukuoka 814-0913, Japan E-mail: takkajii@mac.com

Key words: mandibular prognathism, candidate genes, plexin A2, semaphorin $3 \mathrm{~A}$, chondrocytes proliferative chondrocytes and suggested that sema3A may affect human chondrocytes via its receptor, plexin A2.

\section{Introduction}

It is evident that mandibular prognathism (Online Mendelian Inheritance in Man \#176700) is a multifactorial phenotype $(1,2)$. To identify the susceptibility loci of mandibular prognathism, the first genome-wide association study (GWAS) was performed using microsatellites in Japanese patients including 240 individuals with mandibular prognathism and 360 individuals who were healthy $(3,4)$. This previous GWAS (4) suggested that six loci [1p22.3, 1q32.2 (Table I), 3q23, 6q23.2, 7q11.22 and 15q22.22] were identified as susceptibility regions of mandibular prognathism. The mutations of synovial sarcoma, $\mathrm{X}$ breakpoint 2 interacting protein, plexin A2 (PLXNA2) (Table II), Ras p21 protein activator 2 , transcription factor 21 , calneuron 1 and RAR (retinoic acid receptor)-related orphan receptor $\alpha$ genes were suggested as candidate genes, respectively.

PLXNA2 gene is located on chromosome 1q32.2 and encodes plexin A2, a member of the plexin-A family of semaphorin co-receptors (5). Semaphorins are a large family of secreted or membrane-bound proteins that mediate repulsive effects on axon path finding during nervous system development (5). Semaphorin 3A (sema3A) is a secreted protein and expressed by osteoblasts, whereas sema3A is not detected in osteoclasts (6). Sema3A exerts an osteoprotective effect by suppressing osteoclastic bone resorption and promoting osteoblastic bone formation. Plexin A2 is expressed in osteoblasts, and it is suggested that sema3A and plexin A2 binding stimulates osteoblast differentiation (6). Yoshida et al (7) reported that sema3A may induce cell migration, proliferation and the odontoblastic differentiation of human dental pulp stem cells. However, human mandibular growth consists of a periosteal growth of cortical bone and an endochondral growth of the mandibular condyle (8). Active mandibular growth occurs in an endochondral growth of the condyle (8). 
Gomez et al (9) reported that sema3A and plexin A2 mRNA are expressed in mouse chondrogenic cell line MC 615. However, to the best of our knowledge, there have been no previous studies on the role of sema3A or plexin A2 in human chondrocytes.

The objectives of the present study were to examine the function of sema3A and its receptor, plexin $\mathrm{A} 2$, in human chondrocytes.

\section{Materials and methods}

Cell culture. Normal human chondrocytes (PromoCell GmbH, Heidelberg, Germany) were seeded into a T25 culture vessel $\left(10,000-20,000\right.$ cells $\left./ \mathrm{cm}^{2}\right)$ and grown in commercial medium (Chondrocyte Growth Medium; PromoCell GmbH) containing $10 \%$ fetal calf serum (PromoCell GmbH). Cultures were maintained at $37^{\circ} \mathrm{C}$ in a humidified atmosphere of $5 \% \mathrm{CO}_{2}$ and $95 \%$ air, and the medium was changed every 2-3 days. Subcultures were obtained by removing the cells from the dish using $0.025 \%$ trypsin in 2-[4-(2-Hydroxyethyl)-1-piperazinyl] ethanesulfonic acid (HEPES) buffered saline solution containing $0.01 \%$ ethylenediaminetetraacetic acid (EDTA) (PromoCell GmbH).

Cells were seeded into $100 \mathrm{~mm}$ diameter culture plates. After 1 day, they were exposed to new media with either: i) A $100 \mathrm{ng} / \mathrm{ml}$ concentration, the concentration determined in a previous study (7), of recombinant human sema3A (R\&D Systems, Inc., Minneapolis, MN, USA; high); ii) A $1 \mathrm{ng} / \mathrm{ml}$ concentration of sema3A (low); or iii) without sema3A (control). The effects of sema3A were analyzed at days 7 and 14 of culturing, and representative data were obtained from five culture plates of each group.

Protein assay and type II collagen and human parathyroid hormone-related peptide (PTHrP) receptor 1 (PTH-RI) concentration determination. Cells and extracellular matrices were assayed for concentrations of PTH-R1 on days 7 and 14 of culturing using an Enzyme-linked Immunosorbent assay kit (cat no. SEC743Hu; Cloud-Clone Corp., Houston, TX, USA) as previously described (10). Cells and extracellular matrices were detached with $0.025 \%$ trypsin in HEPES buffered saline solution containing $0.01 \%$ EDTA, collected by centrifugation $\left(220 \mathrm{x} \mathrm{g}\right.$ for $3 \mathrm{~min}$ at $4^{\circ} \mathrm{C}$ ), washed three times, resuspended in $1 \mathrm{X}$ PBS, subject to ultrasonication, and centrifuged $(1,500 \mathrm{x} \mathrm{g}$ for $10 \mathrm{~min}$ at $4^{\circ} \mathrm{C}$ ) to remove cellular debris in accordance with the manufacturer's protocol.

The cells and extracellular matrices were also assayed for concentrations of type II collagen using an enzyme immunoassay kit (Type II Collagen Detection kit; Chondrex, Inc., Redmond, WA, USA) as previously described $(11,12)$. In accordance with the manufacturer's protocol, the cells and extracellular matrices were solubilized by pepsin digestion (at $4^{\circ} \mathrm{C}$ for $24 \mathrm{~h}$ ) and elastase digestion (at $4^{\circ} \mathrm{C}$ for $24 \mathrm{~h}$ ) prior to with the assay. Culture media were also assayed for concentrations of type II collagen. Protein content of the cells and extracellular matrices were measured using a bicinchoninic acid assay reagent kit (Thermo Fisher Scientific, Waltham, MA, USA) as previously described $(13,14)$. Bovine serum albumin was used as the control. All assays were performed according to the manufacturer's protocol.
Statistical methods. The data were represented as the mean \pm standard deviation. Representative data were obtained from five culture plates of each group. Parametric tests were used in the present study as the distribution of the concentrations of type II collagen, PTH-R1 and the protein expression levels of control, low and high sema3A groups were normally distributed. One-way analysis of variance was used to compare the protein content and concentrations of type II collagen and PTH-R1 among three groups. Post hoc multiple comparisons were performed using Bonferroni's test. Statistical analyses were performed using SPSS version 23.0 statistical package (IBM Corporation, Armonk, NY, USA). $\mathrm{P}<0.05$ was considered to indicate a statistically significant difference.

\section{Results}

Evaluation of human chondrocytes response to sema3A treatment. Fig. 1 reveals the effect of recombinant human sema3A on the morphology of human chondrocytes. At culture day 7 , the cells were polygonal, and low and high concentrations of exogenous sema3A appeared to promote the growth of chondrocytes compared with the control. At culture day 14, the cells remained polygonal in the three groups.

Fig. 2 demonstrates the mean \pm standard deviation of the protein content, in accordance with cell growth and accumulation of extracellular matrices, of human chondrocytes. At culture day 7, high and low concentrations of exogenous sema3A significantly increased the protein content of chondrocytes $(0.044 \pm 0.010$ and $0.051 \pm 0.006 \mathrm{mg} / \mathrm{ml}$, respectively) compared with the control $(0.017 \pm 0.005 \mathrm{mg} / \mathrm{ml})(\mathrm{P}=0.0008$ and 0.00002 , respectively). At culture day 14 , a high concentration of sema3A significantly increased the protein content of chondrocytes $(0.174 \pm 0.020 \mathrm{mg} / \mathrm{ml})$ compared with the control $(0.124 \pm 0.014 \mathrm{mg} / \mathrm{ml})(\mathrm{P}=0.002)$.

Effect of sema3A on type II collagen expression in human chondrocytes. Fig. 3 presents the mean \pm standard deviation of concentrations of type II collagen in the culture medium of human chondrocytes. At culture day 7, exogenous sema3A dose-dependently decreased the concentrations of type II collagen in the culture medium of chondrocytes, although the differences were not statistically significant among the three groups. At culture day 14, the concentration of type II collagen in the culture medium of chondrocytes was not detected in the three groups. Concentrations of type II collagen in cells and extracellular matrices were not also detected in the three groups.

Effects of sema3A on PTH-R1 expression in human chondrocytes. Fig. 4 presents the mean \pm standard deviation of concentrations of PTH-R1 in human chondrocytes. At culture day 7, neither high nor low concentrations of exogenous sema3A significantly influenced the concentration of PTH-R1 of chondrocytes $(0.241 \pm 0.036$ and $0.242 \pm 0.029 \mathrm{ng} / \mathrm{ml}$, respectively) compared with the control $(0.253 \pm 0.084 \mathrm{ng} / \mathrm{ml})$. At culture day 14 , a high concentration of sema3A significantly decreased the concentration of PTH-R1 in chondrocytes $(0.211 \pm 0.017 \mathrm{ng} / \mathrm{ml})$ when compared with the control $(0.310 \pm 0.053 \mathrm{ng} / \mathrm{ml})(\mathrm{P}=0.004)$. 
Table I. Results of a previous genome-wide association of mandibular prognathism using microsatellite markers.

\begin{tabular}{|c|c|c|c|c|c|c|c|c|}
\hline \multirow[b]{2}{*}{ Microsatellite } & \multirow[b]{2}{*}{ Cytobands } & \multirow[b]{2}{*}{ Alleles (n) } & \multirow[b]{2}{*}{ Significant allele ${ }^{\mathrm{a}}$} & \multicolumn{2}{|c|}{ Allele frequency } & \multicolumn{2}{|c|}{$\begin{array}{l}\text { Fisher's exact } \\
\text { test P-value }\end{array}$} & \multirow{2}{*}{$\begin{array}{l}\text { Odds ratio (95\% } \\
\text { confidence interval) }\end{array}$} \\
\hline & & & & Cases & Controls & $2 \times 2$ & $2 \mathrm{xm}$ & \\
\hline$D 1 S 1358 i$ & $1 \mathrm{q} 32.2$ & 7 & 92 & 0.362 & 0.465 & 0.000422 & 0.007 & $0.65(0.51-0.83)$ \\
\hline
\end{tabular}

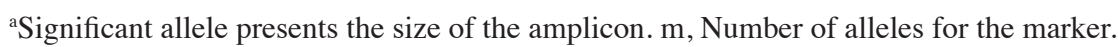

Table II. Information on nearest candidate gene of susceptibility locus obtained from previous genome-wide association study of mandibular prognathism using microsatellites.

\begin{tabular}{lccccc}
\hline & & \multicolumn{2}{l}{ Physical position of amplicon } & & \\
\cline { 3 - 5 } Microsatellite & Cytobands & From & To & Nearest gene & Gene location $^{\text {a }}$ \\
\hline D1S1358i & $1 \mathrm{q} 32.2$ & 208365606 & 208365706 & PLXNA2 & (chr1: 208200588 - 208391267)
\end{tabular}

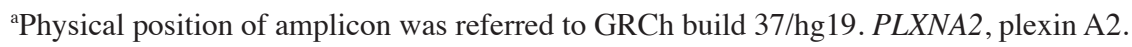

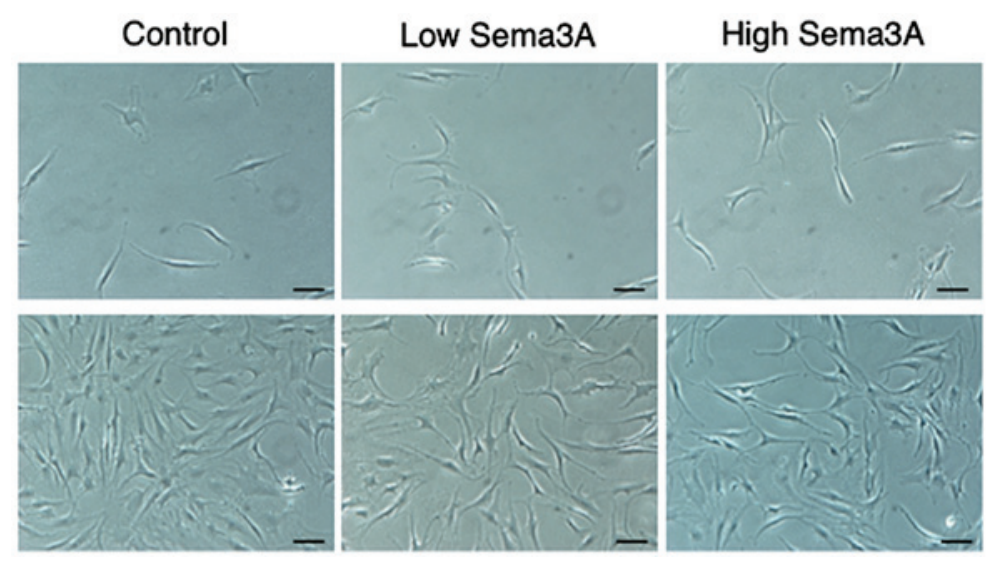

Figure 1. Effect of exogenous sema3A on the morphology of human chondrocytes. Cells cultured for 1 day were exposed to $1 \mathrm{ng} / \mathrm{ml}$ (low) or $100 \mathrm{ng} / \mathrm{ml}$ (high) sema3A for 7 or 14 days in $100 \mathrm{~mm}$ diameter culture plates. Upper lane, day 7; lower lane, day 14. Scale bars, $100 \mu \mathrm{m}$. Sema3A, semaphorin 3A.
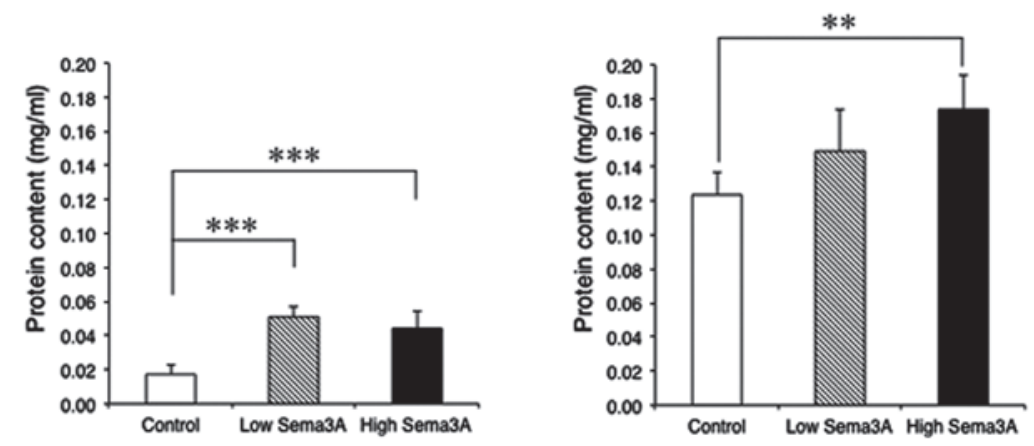

Figure 2. Protein content in human chondrocytes and matrices in the absence or presence of exogenous sema3A. Cells cultured for 1 day were grown without any addition (control), with $1 \mathrm{ng} / \mathrm{ml} \mathrm{sema3A}$ (low) or $100 \mathrm{ng} / \mathrm{ml}$ sema3A (high). Left, day 7 ; right, day 14. The data represent the mean \pm standard deviation of five samples. ${ }^{* * *} \mathrm{P}<0.001$ and ${ }^{* *} \mathrm{P}<0.01$ with comparisons shown by lines. Sema3A, semaphorin $3 \mathrm{~A}$.

\section{Discussion}

To investigate the effects of sema3A on the various functions of human dental pulp stem cells, Yoshida et al (7) added a $10 \mathrm{ng} / \mathrm{ml}$ concentration of recombinant human sema3A in medium for human dental pulp stem cells. To examine the 


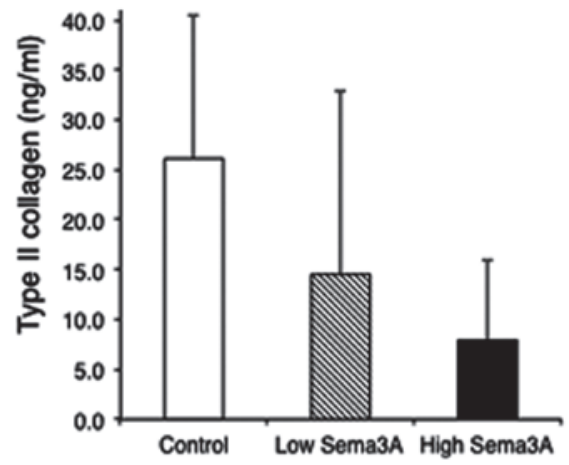

Figure 3. Concentration of type II collagen in culture medium of human chondrocytes at culture day 7 in the absence or presence of exogenous sema3A. Cells cultured for 1 day were grown without any addition (control), with $1 \mathrm{ng} / \mathrm{ml}$ sema3A (low) or $100 \mathrm{ng} / \mathrm{ml} \mathrm{sema} 3 \mathrm{~A}$ (high). The data represent the mean \pm standard deviation of five samples. Sema3A, semaphorin 3A.

function of sema3A in the regulation of osteoclast differentiation, Hayashi et al (6) added a $500 \mathrm{ng} / \mathrm{ml}$ concentration of recombinant sema3A in medium for osteoblasts. The concentrations of recombinant human sema3A used in the present study were selected according to these previous studies.

Type II collagen produced by cells is incorporated into the extracellular matrix $(11,12)$. However, in the present study, type II collagen was not detected in cells and matrix, nevertheless type II collagen was digested by pepsin and elastase for solubilizing collagen. Instead of type II collagen in extracellular matrix, concentrations of type II collagen in culture medium were measured out, which was already soluble.

Sema3A is expressed in osteoblasts (6). Plexin A2, which is a semaphorin receptor, is also expressed in osteoblasts, and it has been suggested that sema $3 \mathrm{~A}$ and plexin $\mathrm{A} 2$ binding stimulates osteoblast differentiation (6). Gomez et al (9) reported that sema3A and plexin A2 mRNA were expressed in a mouse chondrogenic cell line. In the present study, the addition of recombinant human sema3A significantly $(\mathrm{P}<0.001)$ increased the protein content of human chondrocytes (Fig. 2). Protein content is thought to indicate the degree of cell growth and accumulation of extracellular matrices $(13,14)$. The results of the present study and a previous study (9) therefore suggest that plexin A2 may be expressed in not only mouse but also human chondrocytes, and that exogenous sema 3 A may bind plexin A2 on proliferative human chondrocytes and induce the acceleration of cell growth and/or accumulation of extracellular matrices of chondrocytes, although the present study did not assert whether the expression of plexin A2 is constant or regulated by exogenous sema $3 \mathrm{~A}$.

Active mandibular growth occurs in an endochondral growth of the condyle of the temporomandibular joint (8). In the temporomandibular joint, endogenous cytokines are reportedly produced by non-inflammatory cells including osteoblasts and chondrocytes and interact with their receptors (13). The PTHrP gene is located on chromosome 12p12.1-p11.2 and encodes a member of the parathyroid hormone family. The protein PTHrP, via its receptor, PTH-R1, regulates endochondral bone development. The PTHrP ligand is expressed in mouse undifferentiated (proliferative) chondrocytes in the growth plate of developing bones $(15,16)$. PTH-R1 is expressed in mouse chondrocytes located mainly in the proliferative zone and the hypertrophic zone of the growth plate (15-17). Expression of the $P T H-R I$ gene coincides with the type II collagen gene (16). Activation of PTH-R1 interferes with the early stages of chondrogenesis through the cyclic AMP/protein kinase A signaling pathway (18). Namely, PTH-R1 functions to maintain proliferative chondrocytes and delays the production of hypertrophic chondrocytes in mice (18). Indian hedgehog is expressed in pre-hypertrophic chondrocytes and stimulates the production of PTHrP in mice $(18,19)$. Experiments using chimaeric mice (19) revealed that a negative feedback loop functions in chondrogenesis. In the present study, to examine whether sema3A is associated with the endochondral growth of the condyle of the temporomandibular joint, effects of exogenous sema3A on PTH-R1 in human chondrocytes were preliminarily investigated.

In the present study, the addition of a high concentration $(100 \mathrm{ng} / \mathrm{ml})$ of recombinant human sema3A significantly $(\mathrm{P}=0.002)$ decreased the expression of PTH-R1 in human chondrocytes at culture day 14 (Fig. 4). The novel results of the present study suggested that exogenous sema3A may function on plexin A2 in proliferative human chondrocytes and suppresses PTH-R1 and/or PTHrP expression in proliferative human chondrocytes, although the mechanism remains unknown. Suppression of PTH-R1 and/or PTHrP expression potentially accelerates the differentiation of hypertrophic chondrocytes and the subsequent endochondral ossification at
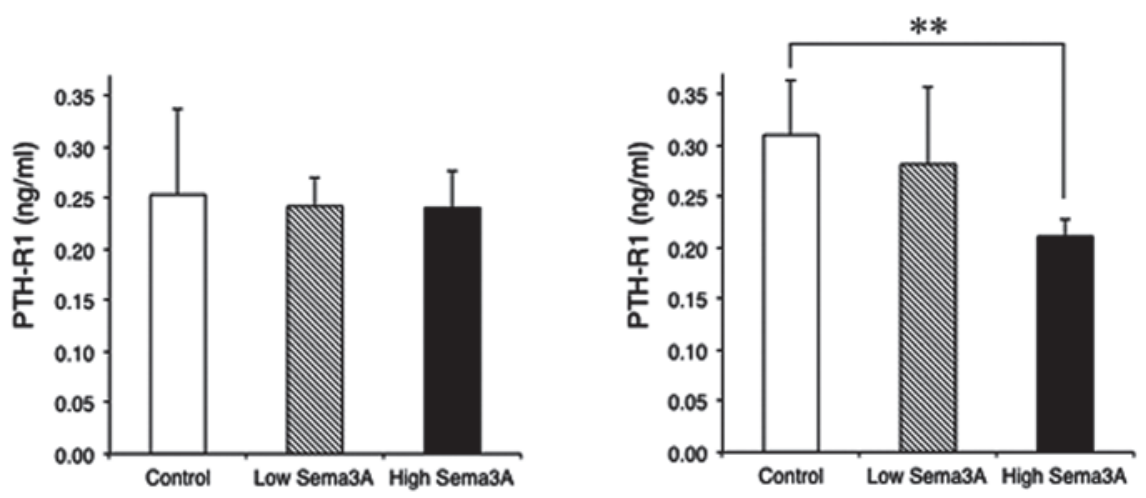

Figure 4. Concentration of PTH-R1 in human chondrocytes and matrices in the absence or presence of exogenous sema3A. Cells cultured for 1 day were grown without any addition (control), with $1 \mathrm{ng} / \mathrm{ml} \mathrm{sema} 3 \mathrm{~A}$ (low) or $100 \mathrm{ng} / \mathrm{ml} \mathrm{sema} 3 \mathrm{~A}$ (high). Left, day 7; right, day 14 . The data represent the mean \pm standard deviation of five samples. ${ }^{* *} \mathrm{P}<0.01$ with comparisons shown by lines. PTH-R1, parathyroid hormone-related peptide receptor 1; sema3A, semaphorin 3A. 
puberty (in other words, early termination of condylar endochondral growth). The mutation of the PLXNA2 gene may inhibit this action of sema3A on chondrocytes and delay this early termination of condylar endochondral growth. Therefore, the mutation of PLXNA2 gene encoding plexin A2 may be a candidate gene of mandibular prognathism, even though the results of the present study were limited.

In the present study, there was no data of expression of sema3A, plexin A2 and PTH-R1 when the calcium concentration was changed. In general, PTH enhances the release of calcium from the large reservoir contained in the bones. PTH and PTH-R1 binding stimulates osteoblasts to increase their expression of receptor activator of nuclear factor $\kappa-B$ (RANKL). The binding of RANKL to RANK stimulates these osteoclast precursors to fuse, forming novel osteoclasts, which ultimately enhances bone resorption (6). Interestingly, Ohta et al (20) reported that plexin A2 mediates cell-cell adhesion via a homophilic binding mechanism under the presence of calcium ions. Therefore, the association between the expression of plexin A2 and calcium concentration will be analyzed in the future.

Another limitation in the present study lies in the 'dedifferentiation' of chondrocytes. Chondrocytes grow and express the phenotypes of chondrocytes in monolayer cultures $(21,22)$. However, in monolayer cultures cultured over two weeks in a previous study, the growing chondrocytes appeared to be dedifferentiated $(21,22)$. Chondrocytes dedifferentiated by monolayer cultures transform into a fibroblast-like morphology and express type I collagen accompanied with a fibroblast-like phenotype $(23,24)$, whereas proliferative chondrocytes are polygonal and express type II collagen accompanied with a chondrocyte phenotype. In the present study, the increased protein content and the decreased type II collagen and PTH-R1 expression in human chondrocytes at culture day 14 may result from the dedifferentiation accelerated by exogenous sema3A.

To facilitate the 'redifferentiation' of the dedifferentiated chondrocytes incubated by monolayer cultures over two weeks, high cell density three-dimensional cultures performed by assembling chondrocyte in alginate beads, synthetic polymer gels or compressing into pellets (spheroid formation) have been attempted $(25,26)$. In future studies, three-dimensional cultures for human chondrocytes will be utilized.

In conclusion, a previous GWAS had revealed PLXNA2 encoding a member of the plexin-A family of semaphorin co-receptors as one of the candidate genes for mandibular prognathism. The present preliminary study proposed that sema3A functions on not only murine but also human chondrocytes and revealed the novel result that exogenous sema3A suppresses the expression of PTH-R1 in human proliferative chondrocytes. Exogenous sema3A may function on human chondrocytes by binding plexin A2. Suppression of PTH-R1 and/or PTHrP expression potentially accelerates the early termination of condylar growth. The mutation of the PLXNA2 gene may delay the early termination of the condylar growth. Therefore, the mutation of the PLXNA2 gene encoding plexin A 2 may be a candidate gene of mandibular prognathism.

\section{Acknowledgements}

Not applicable.

\section{Funding}

The present study was supported by the Japanese Society for the Promotion of Science KAKENHI (Grants-in-Aid for Scientific Research; grant no. JP16K20630) and National Institutes of Health/National Institute if Dental and Craniofacial Research (grant no. R01DE023538).

\section{Availability of data and materials}

The datasets used and/or analyzed during the present study are available from the corresponding author on reasonable request.

\section{Authors' contributions}

TK conceived and designed the study, acquired the data, analyzed and interpreted the data and drafted the article. AO conceived and designed the study and revised the article for important intellectual content. $\mathrm{MH}$ acquired the data, analyzed and interpreted the data and revised the article for important intellectual content. JYamaz analyzed and interpreted the data and revised the article for important intellectual content. JYamas analyzed and interpreted the data and revised the article for important intellectual content. JI conceived and designed the study and revised the article for important intellectual content.

\section{Ethics approval and consent to participate}

Not applicable.

\section{Patients consent for publication}

Not applicable.

\section{Competing interest}

The authors declare that they have no competing interests.

\section{References}

1. Moreno Uribe LM and Miller SF: Genetics of the dentofacial variation in human malocclusion. Orthod Craniofac Res 18 (Suppl 1): 91-99, 2015.

2. Kajii TS and Oka A: Candidate gene analyses of mandibular prognathism. J Dent Oral Biol 2: 1068, 2017.

3. Ikuno K, Kajii TS, Oka A, Inoko H, Ishikawa H and Iida J: Microsatellite genome-wide association study for mandibular prognathism. Am J Orthod Dentofacial Orthop 145: 757-762, 2014.

4. Saito F, Kajii TS, Oka A, Ikuno K and Iida J: Genome-wide association study for mandibular prognathism using microsatellite and pooled DNA method. Am J Orthod Dentofacial Orthop 152: 382-388, 2017.

5. Wray NR, James MR, Mah SP, Nelson M, Andrews G, Sullivan PF, Montgomery GW, Birley AJ, Braun A and Martin NG: Anxiety and comorbid measures associated with PLXNA2. Arch Gen Psychiatry 64: 318-326, 2007.

6. Hayashi M, Nakashima T, Taniguchi M, Kodama T, Kumanogoh A and Takayanagi H: Osteoprotection by semaphorin 3A. Nature 485: 69-74, 2012.

7. Yoshida S, Wada N, Hasegawa D, Miyaji H, Mitarai H, Tomokiyo A, Hamano S and Maeda H: Semaphorin 3A induces odontoblastic phenotype in dental pulp stem cells. J Dent Res 95: 1282-1290, 2016

8. Björk A: Prediction of mandibular growth rotation. Am J Orthod 55: 585-599, 1969. 
9. Gomez C, Burt-Pichat B, Mallein-Gerin F, Merle B, Delmas PD, Skerry TM, Vico L, Malaval L and Chenu C: Expression of Semaphorin-3A and its receptors in endochondral ossification: Potential role in skeletal development and innervation. Dev Dyn 234: 393-403, 2005.

10. Chang WM, Lin YF, Su CY, Peng HY, Chang YC, Hsiao JR, Chen CL, Chang JY, Shieh YS, Hsiao M, et al: Parathyroid hormone-like hormone is a poor prognosis marker of head and neck cancer and promotes cell growth via RUNX2 regulation. Sci Rep 7: 41131, 2017.

11. Gründer T, Gaissmaier C, Fritz J, Stoop R, Hortschansky P, Mollenhauer J and Aicher WK: Bone morphogenetic protein (BMP)-2 enhances the expression of type II collagen and aggrecan in chondrocytes embedded in alginate beads. Osteoarthritis Cartilage 12: 559-567, 2004.

12. Tekari A, Luginbuehl R, Hofstetter W and Egli RJ: Chondrocytes expressing intracellular collagen type II enter the cell cycle and co-express collagen type I in monolayer culture. J Orthop Res 32 : $1503-1511,2014$

13. Kajii TS, Okamoto T, Yura S, Mabuchi A and Iida J: Elevated levels of beta-endorphin in temporomandibular joint synovial lavage fluid of patients with closed lock. J Orofac Pain 19: 41-46, 2005.

14. Luppanapornlarp S, Kajii TS, SuraritR and Iida J: Interleukin-1beta levels, pain intensity, and tooth movement using two different magnitudes of continuous orthodontic force. Eur J Orthod 32 596-601, 2010

15. Karaplis AC, Luz A, Glowacki J, Bronson RT, Tybulewicz VL, Kronenberg HM and Mulligan RC: Lethal skeletal dysplasia from targeted disruption of the parathyroid hormone-related peptide gene. Genes Dev 8: 277-289, 1994.

16. Shukunami C, Shigeno C, Atsumi T, Ishizeki K, Suzuki F and Hiraki Y: Chondrogenic differentiation of clonal mouse embryonic cell line ATDC5 in vitro: Differentiation-dependent gene expression of parathyroid hormone $(\mathrm{PTH}) / \mathrm{PTH}-$ related peptide receptor. J Cell Biol 133: 457-468, 1996.

17. Amizuka N, Kwan MY, Goltzman D, Ozawa H and White JH: Vitamin D3 differentially regulates parathyroid hormone/parathyroid hormone-related peptide receptor expression in bone and cartilage. J Clin Invest 103: 373-381, 1999.
18. Kronenberg HM: Developmental regulation of the growth plate. Nature 423: 332-336, 2003.

19. Chung UI, Schipani E, McMahon AP and Kronenberg HM: Indian hedgehog couples chondrogenesis to osteogenesis in endochondral bone development. J Clin Invest 107: 295-304, 2001.

20. Ohta K, Mizutani A, Kawakami A, Murakami Y, Kasuya Y, Takagi S, Tanaka H and Fujisawa H: Plexin: A novel neuronal cell surface molecule that mediates cell adhesion via a homophilic binding mechanism in the presence of calcium ions. Neuron 14: 1189-1199, 1995.

21. Takigawa M, Shirai E, Fukuo K, Tajima K, Mori Y and Suzuki F: Chondrocytes dedifferentiated by serial monolayer culture form cartilage nodules in nude mice. Bone Miner 2: 449-462, 1987.

22. Sandell LJ and Aigner T: Articular cartilage and changes in arthritis. An introduction: Cell biology of osteoarthritis. Arthritis Res 3: 107-113, 2001

23. von der Mark K, Gauss V, von der Mark H and Müller P: Relationship between cell shape and type of collagen synthesised as chondrocytes lose their cartilage phenotype in culture. Nature 267: 531-532, 1977.

24. Benya PD, Padilla SR and Nimni ME: Independent regulation of collagen types by chondrocytes during the loss of differentiated function in culture. Cell 15: 1313-1321, 1978

25. Chen G, Sato T, Ushida T, Hirochika R and Tateishi T: Redifferentiation of dedifferentiated bovine chondrocytes when cultured in vitro in a PLGA-collagen hybrid mesh. FEBS Lett 542: 95-99, 2003.

26. Caron MM, Emans PJ, Coolsen MME, Voss L, Surtel DA, Cremers A, van Rhijn LW and Welting TJ: Redifferentiation of dedifferentiated human articular chondrocytes: Comparison of 2D and 3D cultures. Osteoarthritis Cartilage 20: 1170-1178, 2012. 